\author{
Fabrizio Branca \\ Selim Orgül \\ Claudia Zawinka \\ Graziella Reinhard \\ Josef Flammer
}

\section{Retinal vascular diameter in young subjects with a vasospastic propensity}

Received: 29 March 2005

Revised: 5 June 2005

Accepted: 23 July 2005

Published online: 23 August 2005

(C) Springer-Verlag 2005
F. Branca $\cdot$ S. Orgül $(\bowtie) \cdot$ C. Zawinka ·

G. Reinhard · J. Flammer

University Eye Clinic of Basel,

Mittlere Strasse 91,

P.O Box 4012 Basle, Switzerland

e-mail: sorguel@uhbs.ch

Tel.: +41-61-2658633

Fax: +41-61-2658745

\begin{abstract}
Purpose: Retinal vascular diameters have recently been shown not to be related to an increased risk of open-angle glaucoma. Because vasospastic propensity has been suggested to represent a risk factor for various ocular diseases, especially glaucoma, the steady-state retinal vascular diameter in subjects with a propensity for systemic vascular dysregulation was compared with a group of age-matched gender-matched controls. Methods: Thirty healthy nonsmoking individuals [female/male 26/4; mean \pm SD age $22.8 \pm 3.4$ (range 18-31) years] were enrolled into the study. Subjects were classified as having vasospasm (15 subjects) if they related a clear history of frequently cold hands and as healthy subjects (15 subjects) if they denied such a history. Vasospastic propensity or the absence of it had to be confirmed by nail-fold capillaroscopy.
\end{abstract}

Vascular diameter of retinal vessels was measured repeatedly on two days with the retinal vessel analyser and corrected for perfusion pressure, age, and refraction. Results: Neither retinal arteriole diameter $(P=0.30)$ or retinal venule diameter $(P=0.49)$, nor retinal arteriole-to-venule ratio $(P=0.96)$, differed between the two experimental groups. Conclusions: Although vasospastic propensity has been suggested to represent a risk factor in various ocular diseases, the steady-state retinal vessel diameters are not altered in healthy vasospastic subjects. It is probable that the steadystate retinal vessel diameters are no adequate risk indicators for the haemodynamic risk in diseases such as glaucoma.

Keywords Glaucoma · Retina Vascular dysregulation · Vasospasm

\section{Introduction}

Structural changes in the retinal vasculature have long been advocated to represent important predictors of systemic vascular disease [37]. However, qualitative assessment of retinal vessels, using ophthalmoscopy, has a poor reproducibility [4]. More recent studies have demonstrated that retinal microvasculature may show abnormalities related to elevated concurrent blood pressure in older people $[25,39$, $42]$ and to cardiovascular complications [6, 26, 27, 38, 40, 41, 43, 44]. From a functional perspective, diseases with vascular dysregulation have been reported to induce vaso- spasms in the retinal vessels [2, 17, 24], and retinal blood flow abnormalities have been reported in otherwise healthy subjects with a propensity for systemic vascular dysregulation [13]. It has been suggested that such alterations may play a role in the pathogenesis of glaucoma $[8,13]$ and also in other ocular diseases [9]. Notwithstanding, a recent study suggested that baseline retinal vessel diameters do not predict the incidence of glaucomatous changes in the optic disc [21]. However, the latter study included only subjects aged at least 55 years, possibly excluding patients who may have developed glaucoma from vascular dysregulation at an earlier age. Therefore, the diameter of the 
retinal vessels in otherwise healthy young vasospastic subjects was compared with a group of age-matched gendermatched controls in a pilot study.

\section{Patients and methods}

Thirty healthy non-smoking individuals, 26 female and four male [mean \pm SD age 22.8 \pm 3.4 (range 18-31) years] were enrolled into the study. All procedures conformed to the Declaration of Helsinki. After approval by the ethics committee, we obtained informed consent from the subjects. A notification in the University Eye Clinic of Basel informed potential volunteers (collaborators, students, parents and friends of patients) of the opportunity to participate in a scientific research project. Subjects were screened for ocular and systemic diseases. A detailed medical and ophthalmic history was recorded, and all subjects completed an ophthalmological examination. Included were only individuals with no history of ocular or systemic disease, no history of chronic or current systemic or topical medication, and no history of drug or alcohol abuse. Further inclusion criteria were a normal systolic (100$140 \mathrm{mmHg}$ ) and diastolic $(60-90 \mathrm{mmHg}$ ) blood pressure, a best-corrected visual acuity above 20/25 in both eyes, ametropia within -3 to +3 dioptres of spherical equivalent and less than 1 dioptre astigmatism in each eye, an intraocular pressure (IOP) lower than $20 \mathrm{mmHg}$ in each eye by (Goldman) aplanation tonometry, and no pathological findings after slit-lamp examination and indirect funduscopy.

Subjects were classified as having vasospasm if they related a clear history of frequently cold hands (answering "yes" to the questions: "do you always have cold hands, even during the summer?" and "do other people tell you that you have cold hands?") and as healthy subjects if they reported no such history. Vasospastic propensity or the absence of it had to be confirmed by nail-fold capillaroscopy, the examiner being unaware of the history of cold hands. Subjects with contradictory findings from nail-fold capillaroscopy and history or describing "sometimes having cold hands" were excluded from the present analysis.

\section{Nail-fold capillaroscopy}

Nail-fold capillaroscopy was performed in a room with a constant temperature of approximately $23^{\circ} \mathrm{C}$ (range $21-$ $25^{\circ} \mathrm{C}$ ). Prior to the examination, the hands of the subjects were warmed in a water bath of $40^{\circ} \mathrm{C}$. The skin of the nailfold was made transparent by a drop of oil, rendering the capillaries running parallel to the skin surface and the flow of cellular elements visible under a light microscope. A microscope coupled to a TV monitor, which was coupled to a video-recorder, allowing the observed blood flow to be videotaped and to be analysed off-line was used. After baseline flow measurement, the nail-fold area was cooled at $-15^{\circ} \mathrm{C}$ for $60 \mathrm{~s}$ by rapidly decompressing carbon dioxide, and the occurrence of blood flow standstill was recorded. A closure of one or more visible capillaries with an average stop-time longer than $12 \mathrm{~s}$ was defined as a vasospastic reaction [29].

\section{Retinal vascular diameter}

Vascular diameter of retinal vessels was measured with the retinal vessel analyser (Imdeos, Jena, Germany), a commercially available device allowing high precision with coefficients of variation for repeated measurements below $3 \%[33,35]$. The retinal vessel analyser (RVA) comprises a fundus camera, a video-camera, a real-time monitor, and a personal computer with analysing software for the accurate determination of retinal arteriole and venule diameters. Retinal vessel diameters are analysed in real time with a maximum frequency of $50 \mathrm{~Hz}$. For this purpose the fundus is imaged onto the charge-coupled device chip of the video-camera. The consecutive fundus images are digitised by a frame grabber. In addition, the fundus image can be inspected on the real-time monitor and, if necessary, stored on a video-recorder, allowing either on-line or offline evaluation.

Measurement of retinal vessel diameters is based on adaptive algorithms using the specific absorbing properties of haemoglobin. A region of interest is defined by a rectangle on the screen of the real-time monitor, within which the retinal vessel diameter is calculated along the entire vascular segment. This window can include a retinal arteriole, a retinal venule, or both. The system is able automatically to correct for alterations in luminance as induced, for instance, by slight eye movements, and the system automatically stops the measurement during blinks. To correct for magnification error, we estimated the optic disc size in each subject at the slit-lamp with a Volk $60 \mathrm{D}$ lens [34]. To establish the correspondence between measurements and dimensions in the eye, we assumed that the diameter of the average optic nerve head was $1,850 \mu \mathrm{m}$ in the eye [20]. The relationship between these estimates of optic disc size was used as the basis for correcting for magnification error.

\section{Experimental procedures}

After evaluation of inclusion criteria and nail-fold capillaroscopy, two days of experiment, 1 week apart, were scheduled for each subject.

On each day of experiment, retinal vessel diameters were measured in the morning, after the subject had fasted for $12 \mathrm{~h}$ overnight, in one randomly chosen eye (the same eye 
on both days of experiment). Participants were instructed to abstain from a large meal, alcohol consumption (including alcohol-containing products and drugs), and physical exercise for $24 \mathrm{~h}$ prior to the measurements. On the days of the experiments, the subjects were seated for $30 \mathrm{~min}$ in the laboratory, and local tropicamid was applied in one eye thrice every 5 min for pupil dilation. Blood pressure was measured every $10 \mathrm{~min}$ for at least $30 \mathrm{~min}$. After stabilisation of blood pressure, retinal vessel diameter was assessed. The fellow eye was covered to improve fixation during imaging with the fundus camera. The image of the retina was adjusted on the screen of the real-time monitor, and a region of interest was laid over a $1-1.5 \mathrm{~mm}$-long segment of the inferior major temporal branch arteriole. The measurement site was located at least half a disc diameter away from the margin of the optic disc. The average measurement time was approximately $1 \mathrm{~min}$. The recordings were stored on a videotape, and the inferior major temporal branch venule was evaluated off-line at the same distance from the disc as the arteriole. Following retinal vessel assessment, blood pressure was measured by sphygmomanometry and intraocular pressure was measured by Goldmann aplanation tonometry, after the application of one drop of $0.4 \%$ benoxinate hydrochloride and the staining of the tear film with a strip of fluorescein sodium.

Ocular perfusion pressure (OPP) was calculated by the following formula: $\mathrm{OPP}=(2 / 3[2 / 3 * \mathrm{DBP}+1 / 3 * \mathrm{SBP}])$ - IOP where DBP, SBP, and IOP represent diastolic blood pressure, systolic blood pressure, and intraocular pressure, respectively.

Particular emphasis was put on ensuring the same measurement conditions at the two sessions, especially for the adjustment of brightness control. All measurements executed with the RVA were performed by the same experienced researcher, who, as the investigator doing nailfold capillaroscopy, was blind to the vasospastic propensity of the subjects. For the second measurements, the investigator was blind to the selection of the region of interest in the first measurement. We obtained the second measurements in order to account for the variation of the placement of the measurement window between participants, as well as for physiological variation of retinal vessel diameter. In order to ascertain that repeated measurements were obtained at comparable conditions, we excluded subjects showing a change of more than $8 \%$ between the first and the second measurements.

Although this was a pilot study, sample size calculations were applied. The variability for measurements of the arteriolar diameter was considered for power calculations, because its measurement is prone to a higher variability $[33,35]$. Based on four unpublished series of measurements, the average within-group variability was estimated to be $12 \%$ of the mean. For a statistical power of $80 \%$ and a probability of $5 \%$, to find a difference between groups of
$13 \%$ (slightly higher than the within-group variability), we needed to recruit 14 subjects for each group.

We performed a two-way analysis of variance (vasospastic subjects/non-vasospastic subjects $\times$ measurement 1 / measurement 2), with the two sessions set as repeated measurements, to compare retina arteriolar and venular vessel diameters, as well as the arteriole-to-venule ratio (arteriole diameter/venule diameter) between vasospastic subjects and controls, after correcting the measurements for perfusion pressure, age, and refraction. A $P$ value of 0.05 was considered significant.

\section{Results}

Ten subjects were excluded because of inconsistent findings between history and nail-fold capillaroscopy, five because of bad recordings in nail-fold capillaroscopy, seven because of bad recordings, and three because of a high differences in RVA measurements between the two days of experiment. Recruitment was pursued until 15 vasospastic and 15 age-matched controls had been identified. Age was $23.0 \pm 3.3$ years in vasospastic subjects and $22.7 \pm 3.6$ years in controls $(P=0.78)$. Spherical equivalent for refraction was $-0.50 \pm 1.28$ dioptres in vasospastic subjects and $-0.79 \pm$ 1.19 dioptres in controls $(P=0.53)$.

IOP, SBP, DBP and OPP are detailed in Table 1 for both measurement sessions. None of the haemodynamic parameters, evaluated in a two-way analysis of variance model (vasospastic subjects/non-vasospastic subjects $\times$ measurement 1 /measurement 2) with the two sessions set as repeated measurements, showed a difference between the two experimental groups $(P=0.96, P=0.65$, and $P=0.82$ for SBP, DBP and OPP, respectively). There was no statistical difference between the two sessions $(P=0.19, P=0.21$, and $P=0.30$, respectively), and the two experimental groups were comparable in this regard (interaction between experimental groups and repeated measurements: $P \mathrm{v}=0.77$, $P=0.58$, and $P=0.51$, respectively). IOP in contrast, was

Table 1 Intraocular pressure, systolic blood pressure, diastolic blood pressure, and perfusion pressure at both measurement sessions $($ mean $\pm \mathrm{SD})$

\begin{tabular}{llcc}
\hline Parameter & Session & $\begin{array}{c}\text { Vasospastic } \\
\text { subjects }\end{array}$ & Controls \\
\hline $\begin{array}{l}\text { Intraocular pressure } \\
\text { (mmHg) }\end{array}$ & 1 & $12.2+1.5$ & $13.6+1.9$ \\
Systolic blood pressure & 1 & $12.1+1.5$ & $13.3+1.7$ \\
(mmHg) & 2 & $115.8+13.4$ & $115.2+12.3$ \\
Diastolic blood pressure & 1 & $113.7+14.7$ & $113.8+12.56$ \\
& 2 & $74.1+10.4$ & $75.2+9.7$ \\
Perfusion pressure & 1 & $42.3+10.7$ & $74.5+9.7$ \\
(mmHg) & 2 & $45.3 \pm 7.2$ & $45.4 \pm 7.0$ \\
\hline
\end{tabular}


Table 2 Diameters of retinal arterioles and venules, and arterioleto-venule ratio at both measurement sessions (mean $\pm \mathrm{SD}$ )

\begin{tabular}{llcl}
\hline Parameter & Session & $\begin{array}{l}\text { Vasospastic } \\
\text { subjects }\end{array}$ & Controls \\
\hline Arteriolar diameters $(\mu \mathrm{m})$ & 1 & $126.8 \pm 14.7$ & $121.2 \pm 15.5$ \\
& 2 & $127.6 \pm 16.1$ & $121.3 \pm 15.8$ \\
Venular diameters $(\mu \mathrm{m})$ & 1 & $154.7 \pm 16.4$ & $150.3 \pm 22.8$ \\
& 2 & $155.1 \pm 15.4$ & $149.7 \pm 21.3$ \\
Arteriolar-to-venular ratio & 1 & $0.83 \pm 0.09$ & $0.82 \pm 0.1$ \\
& 2 & $0.83 \pm 0.1$ & $0.83 \pm 0.1$ \\
\hline
\end{tabular}

lower in vasospastic subjects $(P=0.04)$, with no statistical difference between the two sessions $(P=0.16)$ and no statistical significant interaction between experimental groups and repeated measurements $(P=0.35)$.

The measurements for the diameters for the arterioles, the venules, and the arteriole-to-venule ratio were corrected for the potential influence of age, perfusion pressure and refraction. The values are detailed in Table 2 for both measurement sessions. Evaluation of the corrected values in a two-way analysis of variance model (vasospastic subjects/non-vasospastic subjects $\times$ measurement $1 /$ measurement 2), with the two sessions set as repeated measurements, showed no difference between the groups $(P=0.30)$, and there was no statistical difference between the two sessions $(P=0.28)$, the two experimental groups behaving similarly in this regard (interaction between experimental groups and repeated measurements $P=0.48$ ). Retinal venule diameter, evaluated in a similar model, showed no difference between the groups $(P=0.49)$ or between the two sessions $(P=0.94)$, and there was no interaction between the experimental groups and the repeated measurements $(P=0.54)$. Similarly, retinal arteriole-tovenule ratio showed no difference between the groups $(P=0.96)$ or between the two sessions $(P=0.70)$, and there was no interaction between the experimental groups and the repeated measurements $(P=0.99)$. A comparison of the diameters for the arterioles, the venules, and the arterioleto-venule ratio, without correction for the potential influence of age, ocular perfusion pressure and refraction, did not alter these findings.

\section{Discussion}

The present study demonstrated that retinal vascular diameter is not altered in young and otherwise healthy vasospastic subjects. All the vascular measurements were compared after correction for ocular perfusion pressure, age or refraction, but, except for a lower IOP in vasospastic subjects, all factors potentially having some bearing on the retinal vascular diameter, especially ocular perfusion pressure, were comparable between the experimental groups.
The vasospastic syndrome is a condition manifesting as reversible, local or generalised arteriolar constrictions (vasospasms) or inadequate dilation [9], possibly due to a vascular endotheliopathy $[19,28,32]$ and often associated with vasospastic reactions to cold in the nail-fold capillaries, as assessed by nail-fold capillaroscopy [29]. The primary vasospastic syndrome is encountered more often in women than in men, and is characterised by a tendency towards cold hands. The vascular attacks can be provoked by many factors, such as exposure to cold, stress, emotions and nicotine. The observation of parallel changes in peripheral blood flow (fingers) and visual field in vasospastic patients [16] led to the definition of an entity called "presumed ocular vasospastic syndrome" [7]. Additional studies led further support to the idea that some parallelisms in ocular and digital blood flow exist $[11,15]$ and that the presumed ocular vasospastic syndrome is associated with a lack of blood flow autoregulation [12, 14, 18]. Ocular vasospastic phenomena have also been observed directly in patients with unstable primary angina [2] and with migraine [24]. Ocular vasospastic phenomena have been advocated to be a potential risk factor in various ocular conditions, including glaucoma [1], retinal venous occlusion [30], acute ischaemic optic neuropathy [23], and central serous chorioretinopathy [36].

The retinal vessel diameter was assessed with the RVA, a device allowing a high precision for repeated measurements [33, 35] and for which a good ability to detect changes after interventions has been demonstrated [10, 22, 31]. Furthermore, Dorner et al. [5] calculated the diameter of the central retinal artery based on retinal blood flow velocity measurements obtained by laser Doppler velocimetry and colour Doppler imaging as well as retinal venous diameter measurements with the RVA. Their results were in good agreement to in vitro measurements, suggesting a good ability for the RVA to estimate the retinal vascular diameter. Although vessel diameter assessments were based on measurements obtained in $1 \mathrm{~min}$, which prevented vascular pulsation from having a relevant influence on the results, other physiological parameters, for example hormonal effects [3], as well as variability in alignment of the measurement window were likely to influence the measurements and have a relevant bearing on a small sample. For this reason, repeated measurements were obtained on two different days, 1 week apart, and only repeated measurements with a fair reproducibility were considered in the present study. Tropicamid was used to dilate the pupils and, although this substance was not expected to have a vascular effect, one may have to consider a possible effect of this drug on vessel diameter. However, because it was used equally in both groups, it seems unlikely that this substance may have influenced the presented results. A limitation in our study is the fact that only one pair of vessels was assessed within a defined distance from the optic disc. It is thinkable that vessels of a 
smaller calibre, or those in the upper retina, may be more prone to disclose differences between the analysed subjects. Further investigations are needed to evaluate the regional importance of alterations in the calibre of retinal vessels.

The current study suggests that, under steady-state conditions, the retinal vasculature of otherwise healthy vasospastic subjects does not illustrate distinctive features in retinal vascular diameter. A recently published prospective study showed that both retinal arteriole and venule diameters are not related to an increased risk of open-angle glaucoma [21]. Because vasospastic propensity has been suggested to represent a risk factor for various ocular diseases, especially glaucoma [9], the present findings suggest that the assessment of the retinal vascular diameter may not be an adequate approach to assess the haemodynamic risk in glaucoma patients.

\section{References}

1. Anderson DR (1999) Introductory comments on blood flow autoregulation in the optic nerve head and vascular risk factors in glaucoma. Surv Ophthalmol 43 [Suppl 1]:S5-S9

2. Baksi KB, Rateria N (1984) Spasm of the retinal vessels in association with unstable primary angina. Chest $86: 55$

3. Centofanti M, Bonini S, Manni G, Guinetti-Neuschuler C, Bucci MG, Harris A (2000) Do sex and hormonal status influence choroidal circulation? Br J Ophthalmol 84:786-787

4. Dodson PM, Lip GY, Eames SM, Gibson JM, Beevers DG (1996) Hypertensive retinopathy: a review of existing classification systems and a suggestion for a simplified grading system. J Hum Hypertens 10:93-98

5. Dorner GT, Polska E, Garhofer G, Zawinka C, Frank B, Schmetterer L (2002) Calculation of the diameter of the central retinal artery from noninvasive measurements in humans. Curr Eye Res 25:341-345

6. Duncan BB, Wong TY, Tyroler HA, Davis CE, Fuchs FD (2002) Hypertensive retinopathy and incident coronary heart disease in high risk men. $\mathrm{Br} \mathrm{J}$ Ophthalmol 86:1002-1006

7. Flammer J, Gasser P, Prunte C, Yao K (1992) In: Drance SM, Van Buskirk EM, Neufeld AH (eds) Pharmacology of glaucoma, Williams \& Wilkins, Baltimore, pp 273-283

8. Flammer J, Haefliger IO, Orgul S, Resink T (1999) Vascular dysregulation: a principal risk factor for glaucomatous damage? J Glaucoma 8:212-219

9. Flammer J, Pache M, Resink T (2001) Vasospasm, its role in the pathogenesis of diseases with particular reference to the eye. Prog Retin Eye Res 20:319-349
10. Garhofer G, Kopf A, Polska E, Malec M, Dorner GT, Wolzt M, Schmetterer L (2004) Influence of exercise induced hyperlactatemia on retinal blood flow during normo- and hyperglycemia.

Curr Eye Res 28:351-358

11. Gasser P, Orgul S, Dubler B, Bucheli B, Flammer J (1999) Relationship between blood-flow velocities in the ophthalmic artery and in nailfold capillaries. Br J Ophthalmol 83:505

12. Gherghel D, Orgul S, Dubler B, Lubeck P, Gugleta K, Flammer J (1999) Is vascular regulation in the central retinal artery altered in persons with vasospasm? Arch Ophthalmol 117:1359-1362

13. Gherghel D, Orgul S, Gugleta K, Gekkieva M, Flammer J (2000) Relationship between ocular perfusion pressure and retrobulbar blood flow in patients with glaucoma with progressive damage. Am J Ophthalmol 130:597-605

14. Gherghel D, Orgul S, Gugleta K, Flammer J (2001) Retrobulbar blood flow in glaucoma patients with nocturnal over-dipping in systemic blood pressure. Am J Ophthalmol 132:641-647

15. Girardin F, Orgul S, Erb C, Flammer J (1999) Relationship between corneal temperature and finger temperature. Arch Ophthalmol 117:166-169

16. Guthauser U, Flammer J, Mahler F (1988) The relationship between digital and ocular vasospasm. Graefes Arch Clin Exp Ophthalmol 226:224-226

17. Hansen NB, Stonestreet BS, Rosenkrantz TS, Oh W (1983) Validity of Doppler measurements of anterior cerebral artery blood flow velocity: correlation with brain blood flow in piglets. Pediatrics 72:526-531

18. Hasler PW, Orgul S, Gugleta K, Vogten $\mathrm{H}$, Zhao X, Gherghel D, Flammer J (2002) Vascular dysregulation in the choroid of subjects with acral vasospasm. Arch Ophthalmol 120:302-307
19. Henry E, Newby DE, Webb DJ, O'Brien C (1999) Peripheral endothelial dysfunction in normal pressure glaucoma. Investig Ophthalmol Vis Sci 40:1710-1714

20. Hubbard LD, Brothers RJ, King WN, Clegg LX, Klein R, Cooper LS, Sharrett AR, Davis MD, Cai J (1999) Methods for evaluation of retinal microvascular abnormalities associated with hypertension/sclerosis in the Atherosclerosis Risk in Communities study. Ophthalmology 106:2269-2280

21. Ikram MK, de Voogd S, Wolfs RCW, Hofman A, Breteler MMB, Hubbard LD, de Jong PTVM (2005) Retinal vessel diameters and incident openangle glaucoma and optic disc changes: the Rotterdam study. Investig Ophthalmol Vis Sci 46:1182-1187

22. Jean-Louis S, Lovasik JV, Kergoat H (2005) Systemic hyperoxia and retinal vasomotor responses. Investig Ophthalmol Vis Sci 46:1714-1720

23. Kaiser HJ, Flammer J, Messerli J (1996) Vasospasm - a risk factor for nonarteriitic anterior ischemic optic neuropathy? Neuroophthalmology 16:5-10

24. Killer HE, Forrer A, Flammer J (2003) Retinal vasospasm during an attack of migraine. Retina 23:253-254

25. Klein R, Klein BE, Moss SE, Wang Q (1994) Hypertension and retinopathy, arteriolar narrowing, and arteriovenous nicking in a population. Arch Ophthalmol 112:92-98

26. Klein R, Sharrett AR, Klein BE, Chambless LE, Cooper LS, Hubbard LD, Evans G (2000) Are retinal arteriolar abnormalities related to atherosclerosis?: the Atherosclerosis Risk in Communities study. Arterioscler Thromb Vasc Biol 20:1644-1650 
27. Klein R, Klein BE, Moss SE, Wong TY, Hubbard L, Cruickshanks KJ, Palta M (2004) The relation of retinal vessel caliber to the incidence and progression of diabetic retinopathy: XIX: the Wisconsin epidemiologic study of diabetic retinopathy. Arch Ophthalmol 122:76-83

28. Luscher TF (1991) Endothelin: key to coronary vasospasm? Circulation 83:701-703

29. Mahler F, Saner H, Wurbel H, Flammer J (1989) Local cooling test for clinical capillaroscopy in Raynaud's phenomenon, unstable angina, and vasospastic visual disorders. Vasa 18:201-204

30. Messerli J, Flammer J (1996) Zentralvenenthrombosen bei jungeren patienten. Klin Monatsbl Augenheilkd 208:303-305

31. Nagel E, Vilser W, Lanzl I (2004) Age, blood pressure, and vessel diameter as factors influencing the arterial retinal flicker response. Investig Ophthalmol Vis Sci 45:1486-1492

32. Nakamura M, Yoshida H, Arakawa N, Hiramori K (1999) Endothelium-dependent vasodilator response is augmented in peripheral resistance vessels of patients with vasospastic angina. Cardiology 92:85-92
33. Pache M, Nagel E, Flammer J (2002) Reproducibility of measurements with the retinal vessel analyzer under optimal conditions. Klin Monatsbl Augenheilkd 219:523-527

34. Papastathopoulos KI, Jonas JB (1997) Ophthalmoscopic assessment of the size of the optic nerve papilla. Klin Monatsbl Augenheilkd 211:291-295

35. Polak K, Dorner G, Kiss B, Polska E, Findl O, Rainer G, Eichler HG, Schmetterer L (2000) Evaluation of the Zeiss retinal vessel analyser. Br J Ophthalmol 84:1285-1290

36. Prunte C, Flammer J (1996) Choroidal capillary and venous congestion in central serous chorioretinopathy. Am J Ophthalmol 121:26-34

37. Walsh JB (1982) Hypertensive retinopathy. Description, classification, and prognosis. Ophthalmology 89:1127-1131

38. Wong TY, Klein R, Couper DJ, Cooper LS, Shahar E, Hubbard LD, Wofford MR, Sharrett AR (2001) Retinal microvascular abnormalities and incident stroke: the Atherosclerosis Risk in Communities study. Lancet 358:1134-1140

39. Wong TY, Hubbard LD, Klein R, Marino EK, Kronmal R, Sharrett AR, Siscovick DS, Burke G, Tielsch JM (2002) Retinal microvascular abnormalities and blood pressure in older people: the Cardiovascular Health study. Br J Ophthalmol 86:1007-1013
40. Wong TY, Klein R, Sharrett AR, Duncan BB, Couper DJ, Tielsch JM, Klein BE, Hubbard LD (2002) Retinal arteriolar narrowing and risk of coronary heart disease in men and women. The Atherosclerosis Risk in Communities study. JAMA 287:1153-1159

41. Wong TY, Klein R, Sharrett AR, Schmidt MI, Pankow JS, Couper DJ, Klein BE, Hubbard LD, Duncan BB (2002) Retinal arteriolar narrowing and risk of diabetes mellitus in middle-aged persons. JAMA 287:2528-2533

42. Wong TY, Klein R, Klein BEK, Meuer SM, Hubbard LD (2003) Retinal vessel diameters and their associations with age and blood pressure. Investig Ophthalmol Vis Sci 44:4644-4650

43. Wong TY, Klein R, Sharrett AR, Manolio TA, Hubbard LD, Marino EK, Kuller L, Burke G, Tracy RP, Polak JF, Gottdiener JS, Siscovick DS (2003) The prevalence and risk factors of retinal microvascular abnormalities in older persons: the Cardiovascular Health study. Ophthalmology 110:658-666

44. Wong TY, Duncan BB, Golden SH, Klein R, Couper DJ, Klein BEK, Hubbard LD, Sharrett AR, Schmidt MI (2004) Associations between the metabolic syndrome and retinal microvascular signs: the Atherosclerosis Risk in Communities study. Investig Ophthalmol Vis Sci 45:2949-2954 